\title{
Anatomical Organization and Spatiotemporal Firing Patterns of Layer 3 Neurons in the Rat Medial Entorhinal Cortex
}

\author{
Qiusong Tang, ${ }^{1}$ Christian Laut Ebbesen, ${ }^{1,2}$ Juan Ignacio Sanguinetti-Scheck, ${ }^{1}$ Patricia Preston-Ferrer, ${ }^{3}$ \\ Anja Gundlfinger, ${ }^{4}$ Jochen Winterer, ${ }^{4}$ Prateep Beed, ${ }^{4}$ Saikat Ray, ${ }^{1}$ Robert Naumann, ${ }^{1}$ Dietmar Schmitz, ${ }^{4}$ \\ Michael Brecht, ${ }^{1}$ and Andrea Burgalossi ${ }^{3}$ \\ ${ }^{1}$ Bernstein Center for Computational Neuroscience, ${ }^{2}$ Berlin School of Mind and Brain, Humboldt University of Berlin, 10115 Berlin, Germany, ${ }^{3}$ Werner- \\ Reichardt Centre for Integrative Neuroscience, University of Tübingen, 72076 Tübingen, Germany, and ${ }^{4}$ Charité Universitätsmedizin Berlin, 10117 Berlin, \\ Germany
}

Layer 3 of the medial entorhinal cortex is a major gateway from the neocortex to the hippocampus. Here we addressed structure-function relationships in medial entorhinal cortex layer 3 by combining anatomical analysis with juxtacellular identification of single neurons in freely behaving rats. Anatomically, layer 3 appears as a relatively homogeneous cell sheet. Dual-retrograde neuronal tracing experiments indicate a large overlap between layer 3 pyramidal populations, which project to ipsilateral hippocampus, and the contralateral medial entorhinal cortex. These cells were intermingled within layer 3 , and had similar morphological and intrinsic electrophysiological properties. Dendritic trees of layer 3 neurons largely avoided the calbindin-positive patches in layer 2. Identification of layer 3 neurons during spatial exploration $(n=17)$ and extracellular recordings $(n=52)$ pointed to homogeneous spatial discharge patterns. Layer 3 neurons showed only weak spiking theta rhythmicity and sparse head-direction selectivity. A majority of cells ( 50 of 69$)$ showed no significant spatial modulation. All of the $\sim 28 \%$ of neurons that carried significant amounts of spatial information (19 of 69) discharged in irregular spatial patterns. Thus, layer 3 spatiotemporal firing properties are remarkably different from those of layer 2 , where theta rhythmicity is prominent and spatially modulated cells often discharge in grid or border patterns.

Key words: head-direction cell; juxtacellular recordings; layer 3; medial entorhinal cortex; spatial navigation

Significance Statement

Neurons within the superficial layers of the medial entorhinal cortex (MEC) often discharge in border, head-direction, and theta-modulated grid patterns. It is still largely unknown how defined discharge patterns relate to cellular diversity in the superficial layers of the MEC. In the present study, we addressed this issue by combining anatomical analysis with juxtacellular identification of single layer 3 neurons in freely behaving rats. We provide evidence that the anatomical organization and spatiotemporal firing properties of layer 3 neurons are remarkably different from those in layer 2. Specifically, most layer 3 neurons discharged in spatially irregular firing patterns, with weak theta-modulation and head-directional selectivity. This work thus poses constraints on the spatiotemporal patterns reaching downstream targets, like the hippocampus.

\section{Introduction}

Layer 3 of the medial entorhinal cortex (MEC) is a major component of the corticohippocampal memory loop. Within the

\footnotetext{
Received Feb. 19, 2015; revised June 19, 2015; accepted July 15, 2015.

Author contributions: D.S., M.B., and A.B. designed research; Q.T., C.L.E., J.I.S.-S., P.P.-F., A.G., J.W., P.B., S.R., R.N., and A.B. performed research; Q.T., C.L.E., J.I.S.-S.,P.P.-F., A.G., J.W., and P.B. analyzed data; Q.T., M.B., and A.B. wrote the paper.

This work was supported by the Werner Reichardt Centre for Integrative Neuroscience (CIN) at the Eberhard Karls University of Tübingen (CIN is an Excellence Cluster funded by the Deutsche Forschungsgemeinschaft within the framework of Excellence Initiative EX(307), the Humboldt-Universität zu Berlin, Bernstein Center for Computational Neuroscience Berlin (German Federal Ministry of Education and Research, Förderkennzeichen 01GQ1001A), Neuro-
}

MEC, layer 3 is the main recipient of the ascending deep-tosuperficial inputs (Caballero-Bleda and Witter, 1993, 1994; van Haeften et al., 2003; Abbasi and Kumar, 2013), which are then relayed to MEC layer 2 and the hippocampal subfields CA1 and subiculum (Gloveli et al., 1997; Behr et al., 1998). Although previous studies have provided evidence for morphological/electro-

Cure, a Neuro-Behavior European Research Council grant, and the Gottfried Wilhelm Leibniz Prize of the Deutsche Forschungsgemeinschaft. We thank Alexandra Eritja (Tübingen) for excellent assistance with anatomy experiments; Markus Frey (Tübingen) for data analysis; Moritz von Heimendahl for programming; and Andreea Neukirchner Juliane Steger, and Undine Schneeweiß for technical assistance. 
physiological heterogeneity within the layer 3 principal cell population (Germroth et al., 1989; Dickson et al., 1997; Gloveli et al., 1997; Behr et al., 1998; Canto and Witter, 2012), their relationship to in vivo firing patterns and behavior has remained unexplored. Layer 3 pyramidal neurons differ from layer 2 pyramidal cells morphologically and electrophysiologically (Germroth et al., 1989; van der Linden and Lopes da Silva, 1998; Erchova et al., 2004). Interlaminar connectivity and microcircuit structures are also remarkably different between layer 2 and layer 3 of the MEC (Kloosterman et al., 2003; Beed et al., 2010; Varga et al., 2010; Couey et al., 2013; Pastoll et al., 2013; Ray et al. 2014), thus pointing toward possible functional dissociations between the two entorhinal layers (Kitamura et al., 2014).

The discovery of spatially modulated neurons in parahippocampal circuits has been a major milestone in systems neuroscience (Moser et al., 2008; Moser and Moser, 2013). Extracellular recordings revealed a rich repertoire of functionally specialized cell types in the MEC, including grid cells, border cells, head-direction cells, and cells with conjunctive responses (Hafting et al., 2005; Sargolini et al., 2006; Savelli et al., 2008; Solstad et al., 2008; Lever et al., 2009). Classically layer 2 was seen as the home of "pure" grid cells, where head-direction responses are virtually absent (Zhang et al., 2013; but see Tang et al., 2014b). Initial studies also reported large fractions of grid cells in layer 3 , phase locked to the local field potential theta oscillations (4-12 $\mathrm{Hz}$ ), and the large majority of them displayed conjunctive tuning to head direction (Sargolini et al., 2006; Hafting et al., 2008). Accordingly layer 3 might be a source of theta-modulated, directional, and grid signals to both MEC layer 2 and the hippocampus. Other studies have, however, provided divergent views, and have suggested that theta rhythmicity and theta-phase locking might be weaker among layer 3 neurons (Mizuseki et al., 2009; Burgalossi et al., 2011).

Layer 3 neurons provide a massive excitatory input to the hippocampus (Germroth et al., 1989), where most place cells are found and play a crucial role in hippocampal-dependent memory formation (Suh et al., 2011). Thus resolving the functional and temporal properties of layer 3 neurons is crucial for understanding how place memory is implemented at the cellular level.

Here we addressed this issue with a combined anatomical and functional approach (Burgalossi et al., 2011; Tang et al., 2014a). We show that layer 3 principal neurons, albeit differentiable in respect to long-range projection targets, constitute a largely homogeneous neuronal population, both physiologically and morphologically. By recording from identified layer 3 neurons in animals exploring two-dimensional (2D) environments, we provide evidence that head-direction, grid, and theta-rhythmic responses might be very sparse among layer 3 neurons.

\section{Materials and Methods}

All experimental procedures were performed according to the German guidelines on animal welfare under the supervision of local ethics committees.

Anatomy methods. Brain tissue preparation, histochemical and immunohistochemical experiments, and neurobiotin detection were performed as described in Ray et al. (2014) and Tang et al. (2014b). Briefly,

The authors declare no competing financial interests.

Correspondence should be addressed to either of the following: Andrea Burgalossi at the above address, E-mail: andrea.burgalossi@cin.uni-tuebingen.de; or Michael Brecht at the above address, E-mail: michael.brecht@bccn-berlin.de.

R. Naumann's present address: Max Planck Institute for Brain Research, Max-von-Laue-Strasse 4, 60438 Frankfurt am Main, Germany.

DOI:10.1523/JNEUROSCI.0696-15.2015

Copyright $\odot 2015$ the authors $\quad 0270-6474 / 15 / 3512347-09 \$ 15.00 / 0$
Wistar rats (150-400 g) were euthanized by an intraperitoneal injection of $20 \%$ urethane or sodium pentobarbital. Brains were cut on freezing microtome to obtain $20-60-\mu$ m-thick parasagittal sections or tangential sections (parallel to the pial surface). Immunohistochemical stainings for calbindin and the DNA-binding neuron-specific protein NeuN and Purkinje cell protein 4 (PCP4) were performed as previously described on free-floating sections (Ray et al., 2014).

Retrograde neuronal labeling. Retrograde tracer solutions containing cholera toxin subunit B, Alexa Fluor 488 or 546 conjugate (CTB; $0.8 \%$ $\mathrm{w} / \mathrm{v}$ in $\mathrm{PB})$ were injected in juvenile rats $(\sim 150 \mathrm{~g})$ or in postnatal day $(\mathrm{P})$ 23 rats (for in vitro electrophysiology, see below) under ketamine/xylazine anesthesia. Briefly, two small craniotomies were opened above both the contralateral MEC and the ipsilateral hippocampus. Animals were placed in a stereotaxic apparatus and, before injection, layer 3 of the MEC was localized by electrophysiological mapping with low-resistance electrodes (1-3 M $\Omega$ ), based on characteristic signatures of the local field potential and neuronal spiking activity in MEC layers 2 and 1 (Quilichini et al., 2010). Hippocampal injections were aimed at the pyramidal layer, which was localized by the characteristic sharp-wave/ripple activity patterns. Glass electrodes with a tip diameter of $10-20 \mu \mathrm{m}$, filled with CTB solution, were then lowered into the target region. Tracer solutions $(\sim 0.3-0.8 \mu \mathrm{l})$ were slowly injected using positive pressure. After the injections, the pipettes were left in place for several minutes and slowly retracted. The craniotomies were closed by application of silicone and dental cement. The animals survived for 3-7 d before being transcardially perfused or sacrificed for in vitro electrophysiology (below).

Analysis of anatomy data. For neuron counting, regions of interest (ROIs) were selected from tangential sections through layer 3 of the MEC from double-retrograde tracing experiments (as described above, $n=3$ ). Neurons were counted manually with NeuroLucida on $z$-stacks or singleconfocal planes acquired with a confocal microscope Zeiss LSM 710 or Leica TCS SP5. Only ROIs with the highest regional overlap between back-labeled somata were selected for counting.

Reconstructions of dendritic morphologies were performed manually with NeuroLucida and displayed as $2 \mathrm{D}$ projections on the tangential plane (i.e., parallel to the MEC pial surface). For quantitative analysis of the relationship between apical dendritic morphologies of layer 3 neurons and layer 2 calbindin patches, the patches were manually outlined from calbindin stainings on tangential MEC sections; then, the fraction of apical dendrites contained within the patch area was calculated with the NeuroLucida software.

Slice preparation for in vitro electrophysiology. Four to seven days after retrograde neuronal labeling (see above), rats (P26-P29, $n=4$ ) were decapitated following isoflurane anesthesia. Brains were removed and transferred to ice-cold, sucrose-based artificial CSF (ACSF) containing (in $\mathrm{mM}$ ) the following: $87 \mathrm{NaCl}, 75$ sucrose, $26 \mathrm{NaHCO}_{3}, 2.5 \mathrm{KCl}, 1.25$ $\mathrm{NaH}_{2} \mathrm{PO}_{4}, 0.5 \mathrm{CaCl}_{2}, 7 \mathrm{MgCl}_{2}, 25$ glucose, saturated with $95 \% \mathrm{O}_{2}, 5 \%$ $\mathrm{CO}_{2}$, $\mathrm{pH}$ 7.4. Slices $(400 \mu \mathrm{m})$ were cut in a horizontal plane, tilted to the perpendicular axis of the pial surface of the entorhinal cortex on a vibratome (VT1200S, Leica). Slices were stored in an interface chamber $\left(32-34^{\circ} \mathrm{C}\right)$, continuously oxygenized with carbogen, and perfused with ACSF containing the following (in $\mathrm{mM}$ ): $119 \mathrm{NaCl}, 26 \mathrm{NaHCO}_{3}, 10$ glucose, $2.5 \mathrm{KCl}, 2.5 \mathrm{CaCl}_{2}, 1.3 \mathrm{MgCl}_{2}, 1 \mathrm{NaH}_{2} \mathrm{PO}_{4}$, at a rate of $\sim 1$ $\mathrm{ml} / \mathrm{min}$. Slices were allowed to recover for $\geq 1 \mathrm{~h}$ after preparation before they were transferred into the recording chamber.

In vitro electrophysiology and immunohistochemistry. Whole-cell patchclamp recordings (pipette resistance, 2.5-4 M $\Omega$ ) were performed in ACSF near physiological temperature in a submerged-type recording chamber. Fluorescently labeled cells in layer 3 of the MEC were identified using fluorescence microscopy (XM10, Olympus) and infrared differential contrast microscopy (BX51WI, Olympus). For characterization, increasing steps of negative and positive current were injected ( $1 \mathrm{~s}$ duration). The intracellular solution contained the following (in $\mathrm{mM}$ ): $135 \mathrm{~K}$-gluconate, $6 \mathrm{KCl}, 2 \mathrm{MgCl}_{2}$, 0.2 EGTA, $5 \mathrm{Na}_{2}$-phosphocreatine, $2 \mathrm{Na}_{2}$-ATP, $0.5 \mathrm{Na}_{2}$-GTP, 10 HEPES buffer, and $0.2 \%$ biocytin. The $\mathrm{pH}$ was adjusted to 7.2 with $\mathrm{KOH}$. Recordings were performed using Multiclamp 700A/B amplifiers (Molecular Devices). Signals were filtered at $6 \mathrm{kHz}$, sampled at $20 \mathrm{kHz}$, and digitized using the Digidata 1550 and pClamp 10 (Molecular Devices) or custom-written procedures in Igor Pro. 
After recording, slices were transferred into a fixative solution containing $4 \%$ paraformaldehyde in $0.1 \mathrm{M}$ phosphate buffer. Biocytinfilled cells were visualized by streptavidin conjugated to Alexa 647 (diluted 1:500 in PBS containing 1\% Triton). The slices were then mounted in Fluoroshield (Sigma-Aldrich) and analyzed. Image stacks of specimens were imaged on a Leica TCS SP5 confocal microscope (Leica Microsystems).

Juxtacellular and tetrode recordings. Juxtacellular recordings in urethane/ketamineanesthetized animals were obtained in male Wistar rats and were performed essentially as previously described (Klausberger et al., 2003; Ray et al., 2014). Before juxtacellular recordings, mapping experiments with low-resistance electrodes $(0.5-1 \mathrm{M} \Omega)$ were performed to estimate the recording depth of the entorhinal layers, based on known electrophysiological features of the of the entorhinal laminar structure (Quilichini et al., 2010). Morphological identification of a subset of the recorded neurons confirmed the expected laminar location (7 of 7 neurons in layer 3 ).

Juxtacellular recordings in freely moving animals were obtained in male Wistar rats. Experimental procedures, signal acquisition and processing, and animal tracking were performed as recently described (Tang et al., 2014a,b). Twenty-seven juxtacellular recordings were identified [i.e., at least a soma and/or dendrite(s) could be recovered in layer 3]. Two juxtacellular recordings, where cell identification failed but recording sites were localized to MEC layer 3, were included as "nonidentified" recordings. Fifty units were recorded with tetrodes, according to described procedures (Tang et al., 2014b) in Wistar and Long-Evans rats. All tetrode recording experiments were performed in a $1 \times 1 \mathrm{~m}$ arena. Ten juxtacellular recordings were performed in a $1 \times 1 \mathrm{~m}$ arena. The remaining recordings were performed in a $70 \times 70 \mathrm{~cm}$ arena. MEC layer 2 data, shown here for direct comparison, have been published in previous papers (Ray et al., 2014; Tang et al., 2014b).

Theta rhythmicity and theta-phase analysis. Theta rhythmicity of spiking discharge was determined in the following way: first, we calculated the autocorrelation of the spike train, binned in $10 \mathrm{~ms}$ bins; then we calculated the power spectrum of the autocorrelation using the Welch estimate ("pwelch" in Matlab). To measure spiking rhythmicity in the theta band, a "theta-rhythmicity" index was computed, defined as the average power within $1 \mathrm{~Hz}$ of the maximum of the autocorrelation function in the theta range $(4-12 \mathrm{~Hz})$.

For spiking theta-phase analysis, we calculated the locking to theta phase based on spiking discharge in relation to theta rhythm in the local field potential. The local field potential was zero-phase bandpass filtered $(4-12 \mathrm{~Hz})$ and a Hilbert transform was used to determine the instantaneous phase of the theta wave. The strength of locking to theta phase, $S$, and the preferred phase angle, $\varphi$, was defined as the modulus and argument of the Rayleigh average vector of the theta phase at all spike times. Only spikes during running (speed cutoff: $1 \mathrm{~cm} / \mathrm{s}$ for juxtacellular signals, $5 \mathrm{~cm} / \mathrm{s}$ for tetrode recordings) were included in the analysis.

Only cells with firing rate of $>0.5 \mathrm{~Hz}$ were included in the thetarhythmicity and theta-phase analysis. Three juxtacellular recordings were not included in the theta-phase analysis (since local field potential signals were not recorded) but only theta rhythmicity was computed. For direct comparability of MEC layer 2 and layer 3 data, both the analysis procedures and the juxtacellular dataset largely correspond to our recent work (Ray et al., 2014; Tang et al., 2014b)

Analysis of spatial modulation and head directionality. Rate maps, spatial autocorrelations, spatial information (Skaggs et al., 1993), grid scores, border scores, and head directionality were computed as previously described (Tang et al., 2014b) to remain consistent with the criteria of our previous report on MEC layer 2 (Tang et al., 2014b), thus allowing direct comparison with those results (see Figs. 5, 7).

Briefly, grid scores were calculated as previously described (Tang et al., 2014b) by taking a circular sample of the autocorrelogram, centered on, but excluding, the central peak. The Pearson correlation of this circle with its rotation for 60 and $120^{\circ}$ was obtained (on peak rotations) and also for rotations of 30,90 , and $150^{\circ}$ (off-peak rotations). Gridness was defined as the minimum difference between the on-peak rotations and off-peak rotations (Tang et al., 2014b).

Briefly, head-direction tuning was measured as the eccentricity of the circular distribution of firing rates. A cell was defined as head direction if the length of the average vector exceeded the 95th percentile of a distribution of average vector lengths calculated from shuffled data and had a Rayleigh vector length of $>0.3$. For head-direction analysis, a firing-rate inclusion criteria $(>0.5 \mathrm{~Hz})$ was applied. For spatial analysis, both a spatial ( $>50 \%$ spatial coverage) and a firing-rate inclusion criterion $(>0.5 \mathrm{~Hz})$ were applied. Spatial coverage was defined as the fraction of visited pixels (bins) in the arena to the total pixels. Of the 79 recordings 
A

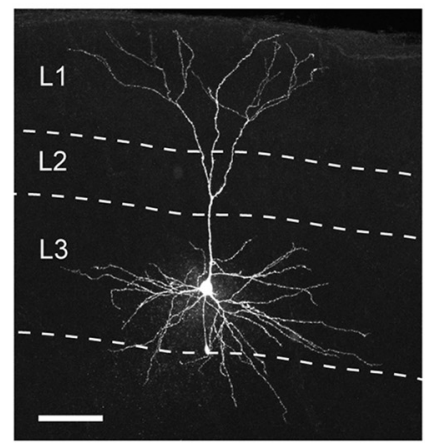

B

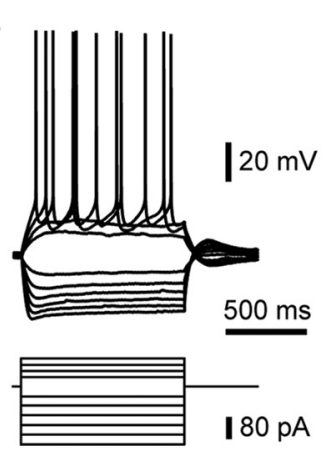

C

\begin{tabular}{|l|l|}
\hline Intrinsic property & mean \pm std \\
\hline Input resistance $(\mathrm{M} \Omega)$ & $131.3 \pm 31.1$ \\
Spike duration $(\mathrm{ms})$ & $2.26 \pm 0.49$ \\
Tau sag potential $(\mathrm{ms})$ & $142.7 \pm 42.0$ \\
Sag potential $(\mathrm{mV})$ & $5.32 \pm 1.15$ \\
$\begin{array}{l}\text { Rebound de- } \\
\text { polarization }(\mathrm{mV})\end{array}$ & $6.47 \pm 1.51$ \\
Adaptation ratio & $0.50 \pm 0.13$ \\
\hline
\end{tabular}

D

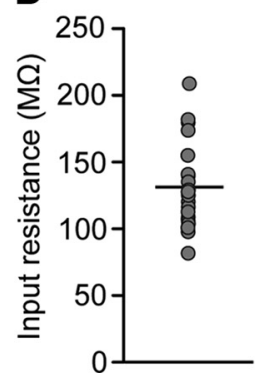

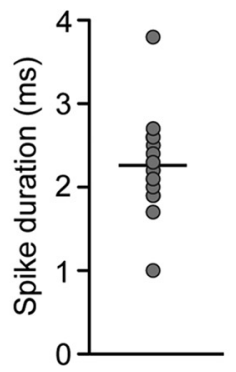
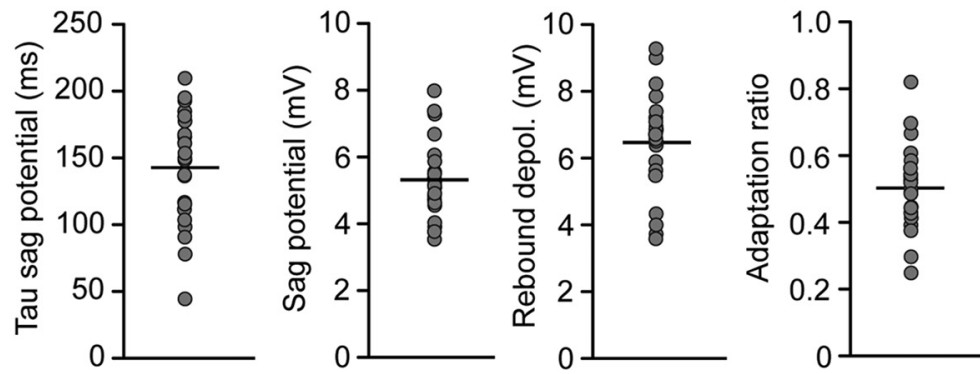

Figure 2. Morphology and intrinsic properties of layer 3 principal neurons in the MEC. A, Maximal intensity projection of a confocal image stack of an exemplary layer 3 pyramidal cell in the MEC. The shown cell was filled with biocytin during electrophysiological recording and counterstained with streptavidin A647 after fixation. Scale bar, $100 \mu \mathrm{m}$. $\boldsymbol{B}$, Representative electrophysiological characterization of a layer 3 pyramidal cell. Hyperpolarizing and depolarizing current steps were applied to determine passive properties and action potential pattern. $C$, Summary table of intrinsic membrane properties of layer 3 pyramidal cells. D, Distribution of intrinsic parameters for all recorded cells. Gray circles represent mean values of individual neurons; black lines are mean values of all neurons $(n=23)$.
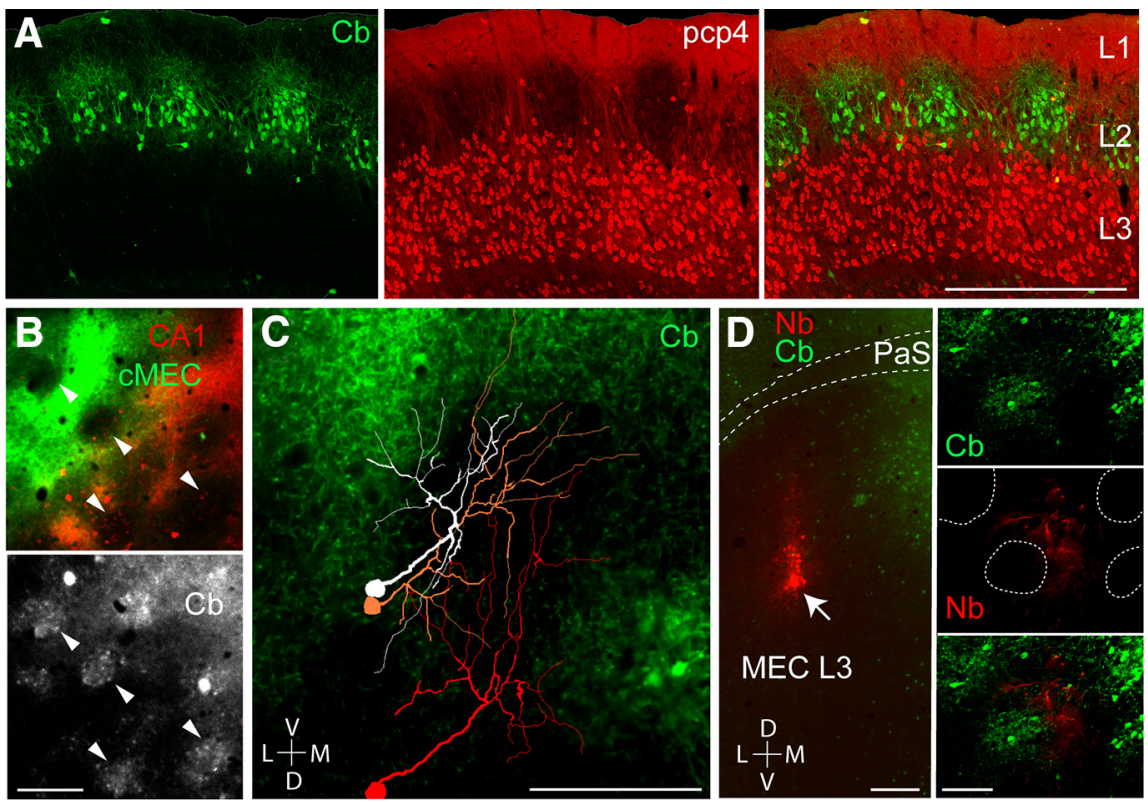

Figure 3. Layer 3 dendrites avoid calbindin-positive pyramidal cell patches in layer 2. A, Sagittal section through the MEC stained for calbindin ( green, left) and PCP4 (red, middle). Right, Overlay. Note the clustering of apical layer 3 dendrites around the calbindin patches in layer 2. Scale bar, $500 \mu \mathrm{m}$. B. Close-up views from a tangential section through superficial MEC layer 2, showing neuropil signal of retrogradely labeled layer 3 neurons, following injections of (TB-Alexa 488 (green) and CTB-Alexa 546 (red) as in Figure 1C, stained for calbindin (gray). Arrowheads indicate calbindin patches. C, Reconstructions of the apical dendritic morphologies of three representative layer 3 pyramidal neurons, superimposed on the calbindin staining in MEC layer 2 (tangential view). Note that the dendrites largely avoid the calbindin territories. Scale bar, $200 \mu \mathrm{m}$. D, Left, Tangential section through layer 3 of the MEC stained for neurobiotin (red) and calbindin (green) showing the site of neurobiotin "spillover" in MEC layer 3, where a cluster of layer 3 neurons is labeled (arrow). Right, A close-up magnification on the apical dendrites: calbindin patches (green, top), neurobiotin-labeled ( $\mathrm{Nb}$ ) dendrites (middle, red), and overlay (bottom). Dotted lines represent patch outlines. Note that the labeled dendrites (red) largely avoid the patch territories (green). Scale bars: left, $200 \mu \mathrm{m}$; right, $100 \mu \mathrm{m}$. D, Dorsal; L, lateral; M, medial; V, ventral. (juxtacellular plus tetrode), 69 recordings (17 identified plus 52 nonidentified recordings) satisfied these criteria and were included in the spatial and head-direction analysis.

None of the layer 3 neurons met our previous grid-cell criteria (Tang et al., 2014b; grid score, $>0.3$; and significant spatial information). Two juxtacellularly recorded and identified L3 neurons showed hexagonally arranged firing fields in the spatial autocorrelation (one cell shown in Tang et al., 2014a); the short duration of the recordings, however, prevented statistical assessment of spatial modulation in these two neurons. Only one neuron (see Fig. 6 , asterisk) met the inclusion criteria for border activity (border score, $>0.5$; and significant spatial information; Tang et al., 2014b). This neuron was classified as a border cell, although the small border score (border score, 0.52; spatially significant with $p=0.03$ ) and visual assessment of the rate map indicated that it might be a false-positive border cell.

\section{Results}

To assess the cytoarchitectonic organization of MEC layer 3, we stained tangential and parasagittal section through the MEC for the neuronal marker NeuN, cytochrome oxidase activity, and cholinergic markers. Unlike MEC layer 2 (Burgalossi et al., 2011; Ray et al., 2014) in all these preparations, layer 3 had a relatively homogeneous appearance (Fig. $1 A, B$; data 
not shown). Next, we sought to determine how the projection patterns of layer 3 neurons were spatially arranged. To this end, we performed double injections of the retrograde tracer CTB in both the ipsilateral hippocampus and the contralateral MEC. Consistent with previous findings (Germroth et al., 1989; Brun et al., 2008; Suh et al., 2011), layer 3 neurons were readily labeled following hippocampal injections. We found, however, that a large fraction of layer 3 neurons also project densely to contralateral MEC (Fig. 1C). This contralateral projection, which originates in layer 3, targeted mostly superficial layers on the contralateral side (data not shown). Tangential sections of the layer 3 cortical sheet stained for both hippocampal-projecting (red) and contralateral MEC-projecting cells (green) provide a particularly clear overview of the distribution of these two cell populations (Fig. 1C). While hippocampalprojecting neurons were arranged in a transverse band (Honda et al., 2012), neurons labeled following contralateral injections were predominantly restricted to a single location, consistent with a pointto-point contralateral connectivity (Fig. $1 C)$. We observed that a large fraction of contralateral-projecting neurons $(\sim 40 \%$, 162 of 397 cells; $n=3$ rats) were also double labeled by the ipsilateral hippocampal injection (Fig. 1D). These data indicate that hippocampally and contralaterally projecting neurons might not form discrete neuronal populations.

To assess morphological characteristics and intrinsic properties, we conducted whole-cell patch-clamp recordings of layer 3 pyramidal cells in slices of the MEC. The majority of recorded neurons $(n=17$ of a total of 23 cells) were labeled post hoc with streptavidin-A647 and could be morphologically identified as pyramidal cells (Fig. $2 A$ ). In addition to the morphological description of the recorded neurons, we also tested their intrinsic properties and spiking behavior by applying a series of hyperpolarizing and depolarizing current steps (Fig. 2B). All intrinsic properties (input resistance, spike duration, tau of the sag potential, sag amplitude, rebound depolarization, and adaptation ratio) were homogeneously distributed among the population of recorded neurons (Fig. 2C,D). In a subset of recorded cells, the projection targets were identified by retrograde tracers from the ipsilateral hippocampus and contralateral MEC (see Materials and Methods; Fig. 1). We did not observe a correlation between projection targets and intrinsic parameters of the neurons (data not shown). Our in vitro electrophysiology analysis thus consolidates the picture of a largely homogenous population of neurons in MEC layer 3.

We next investigated the relationship between layer 3 neurons and the modular architecture of MEC layer 2 pyramidal cells (Ray et al., 2014). PCP4 labels neurons in layer 3 and deep layers of the entorhinal cortex (Lein et al., 2007). Here we show using antibodies against calbindin and PCP4 that the layer 3 apical dendrites tend to form clusters between the calbindin patches in layer 2 (Fig. 3A). To further explore this issue, we analyzed the relationship between the neuropil of retrogradely labeled layer 3 neurons and the layer 2 pyramidal cell patches, identified by calbindin immunoreactivity (Ray et al., 2014). Interestingly, both hippocampal and contralateral-projecting layer 3 cell populations largely avoided the calbindin patches (Fig. $3 B$ ). To clarify this relationship at the single-cell level, we reconstructed the apical dendritic morphology of single layer 3 neurons, labeled juxtacellularly in vivo (Fig. 3C). The majority of dendritic branches from layer 3 cells avoided the calbindin patches (total dendritic length inside vs outside of patches, $900 \pm 101 \mu \mathrm{m}$ vs $7193 \pm 588$ $\mu \mathrm{m}, n=5$; Fig. $3 C$ ), in line with the retrograde-tracing data. Moreover, labeling small "clusters" of layer 3 neurons by neurobiotin spillover led to similar results, i.e., dendritic trees of layer 3 neurons largely avoiding the calbindin-patch territories in superficial layer $2 / 1$ (Fig. 3D). These data suggest that the dendrites 
A
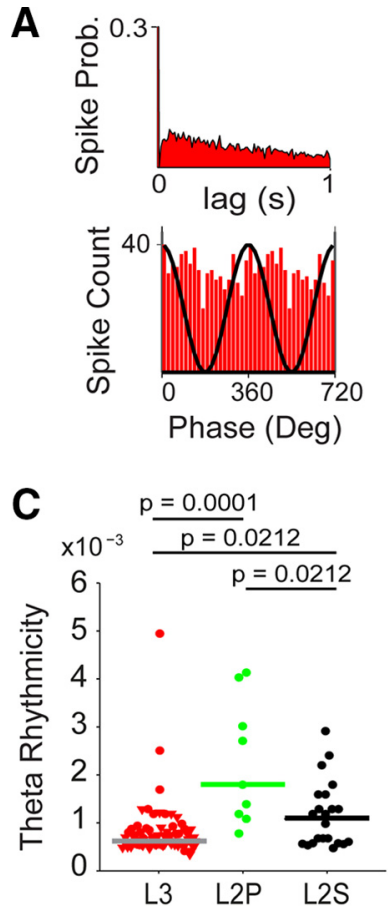

B
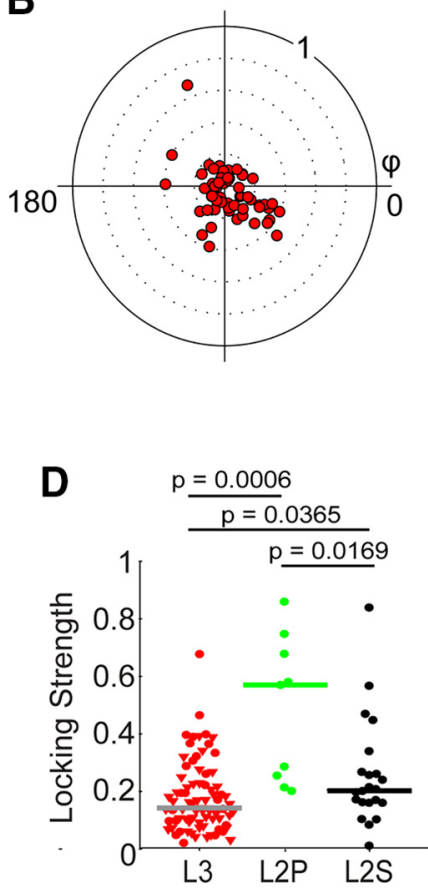

Figure 5. Theta modulation of layers 3 and 2 neurons in the MEC. $\boldsymbol{A}$, Representative spike autocorrelogram (top) and theta-phase histogram of spikes (bottom) of a juxtacellularly recorded and identified MEC layer 3 neuron. Note the absence of theta rhythmicity (top), as in the representative neuron in Figure 4. Bottom, Two repeated cycles; the black sinusoid is a schematic local field potential theta wave for reference. $B$, Polar plot of preferred theta phase (theta peak, $\left.0^{\circ}\right)$ and theta-phase-locking strength $(0-1)$ for layer 3 neurons $(n=79)$. Red dots: cells and single units. Note the nonsignificant theta-phase preference in our dataset ( $p=0.47)$. C, $\boldsymbol{D}$, Theta rhythmicity $(\boldsymbol{C})$ and theta-phase-locking strength $(\boldsymbol{D})$ in MEC L3 (red), identified L2 pyramidal (green), and stellate (black) neurons. Triangles indicate nonidentified layer 3 recordings (juxtacellular plus tetrode). Circles indicate cells recorded and identified juxtacellularly. Horizontal lines indicate medians; $p$ values indicate result of Mann-Whitney $U$ test. All $p$ values are Bonferroni-Holm corrected for multiple comparisons. Data from MEC L2 are from Tang et al. 2014b and are shown for comparison.

from layer 3 pyramidal cells do not sample inputs, which are selective for the calbindin patches (i.e., cholinergic and parasubicular inputs; Ray et al., 2014; Q.T., A.B., and M.B., unpublished observations).

What are the firing properties of layer 3 neurons during spatial navigation? An example of a cell identified in layer 3 is shown in Figure 4 . The cell is a pyramidal neuron with wide-spreading basal dendrites and a single, bifurcating apical dendrite (Fig. 4A). Spiking activity carried a significant amount of spatial information (Skaggs et al., 1993), but no clear spatial firing pattern was revealed by $2 \mathrm{D}$ spatial autocorrelation (Fig. $4 B$ ). The cell's firing was not modulated by head direction (Fig. $4 C$ ) and it lacked theta rhythmicity (Fig. 4D). However, it displayed a clear phase preference near the theta peak (Fig. $4 E$ ). Similarly to this representative neuron, in most recordings from identified layer 3 neurons, we did not observe spike rhythmicity or regular spatial firing patterns (see below). In only two neurons-one of which was located at the layer $2 / 3$ border and showed strongest theta rhythmicity-we observed hexagonal "grid-like" firing (data not shown). The short duration of the recordings, however, prevented statistical assessment of spatial modulation in these two neurons (see Materials and Methods). The discharge properties of the neuron shown in Figure 4 are in many regards prototypic for layer 3 as will be pointed out in the population data shown in the next two figures.

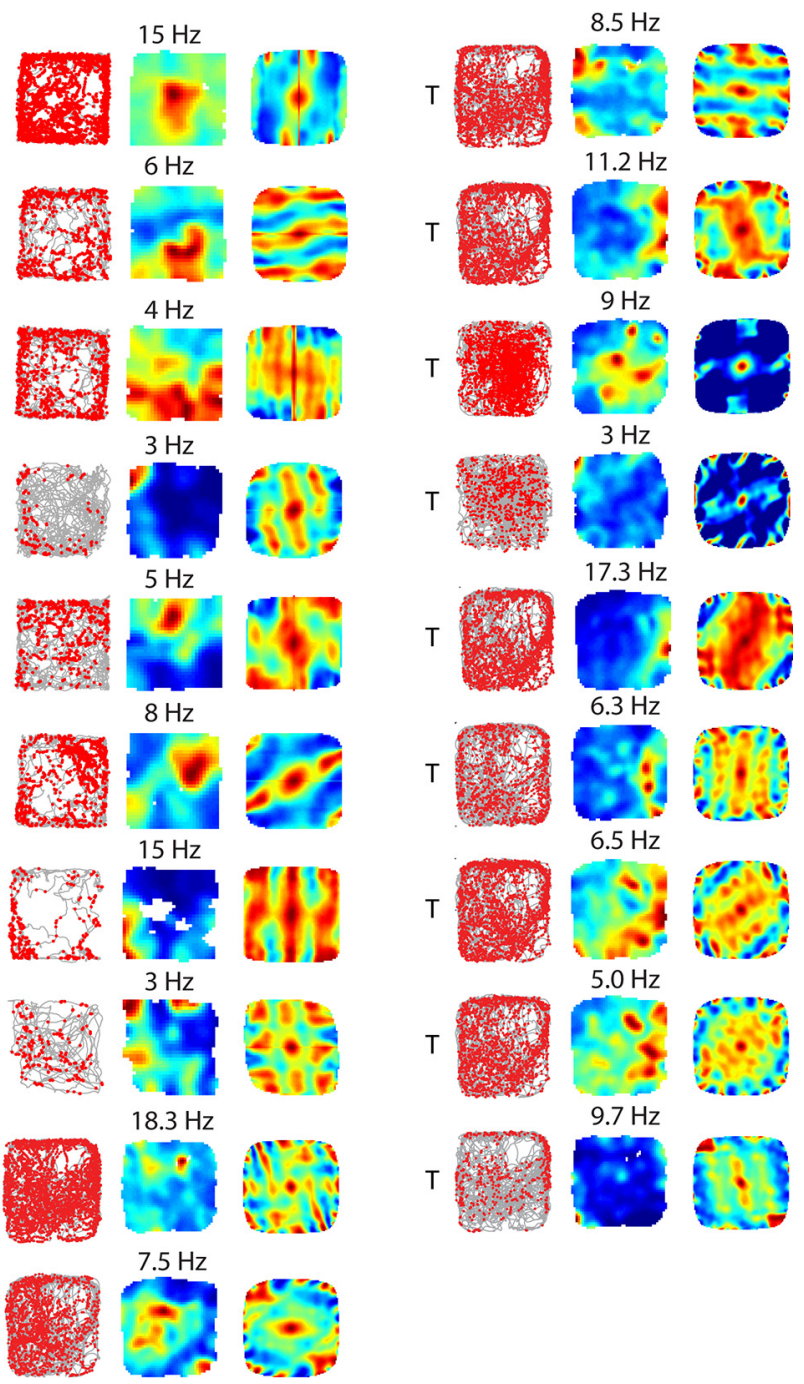

Figure 6. Spatially irregular firing patterns of layer 3 neurons, which carry significant spatial information. Spike-trajectory plot, rate map, and 2D spatial autocorrelation of MEC layer 3 recordings, which carry significant spatial information (see Materials and Methods). Numbers above the rate map indicate maximum firing rate. Tindicates cells recorded with tetrodes $(1 \times$ $1 \mathrm{~m}$ arena); all other cells are from juxtacellular recordings (70 $\times 70 \mathrm{~cm}$ arena). The neuron indicated with the asterisk $\left(^{*}\right)$ met the border criteria (border score, 0.52 ) and was thus included in this category (Fig. 7A; see Materials and Methods).

To clarify the temporal spiking properties of layer 3 neurons relative to local field potential theta oscillations, we combined data from juxtacellular recordings with single units from tetrode recordings. Spatial and temporal analysis of this extended dataset $(n=79)$ confirmed the observations from the identified dataset. First, most layer 3 cells showed weak theta rhythmicity and thetaphase locking strength (Fig. 5A). As a population, layer 3 neurons did not show a significant theta-phase preference $(p=0.47)$, even when only neurons with significant theta-phase locking ( $n=64$ with Rayleigh test, $p<0.01$; Mizuseki et al., 2009) were included ( $p=0.27$; Fig. $5 B$ ). Compared with identified layer 2 pyramidal and stellate cells (Ray et al. 2014), they showed significantly weaker theta rhythmicity $(p=0.0001$ and $p=0.0212$, respectively, Mann-Whitney $U$ test, Bonferroni-Holm corrected for multiple comparisons; Fig. $5 C$ ) and significantly weaker theta-phase locking strength $(p=0.0006$ and $p=0.0365$, respectively, Mann-Whitney $U$ test, Bonferroni-Holm corrected for multiple comparisons; Fig. 5D). Notably, similar results were ob- 
A Layer 3
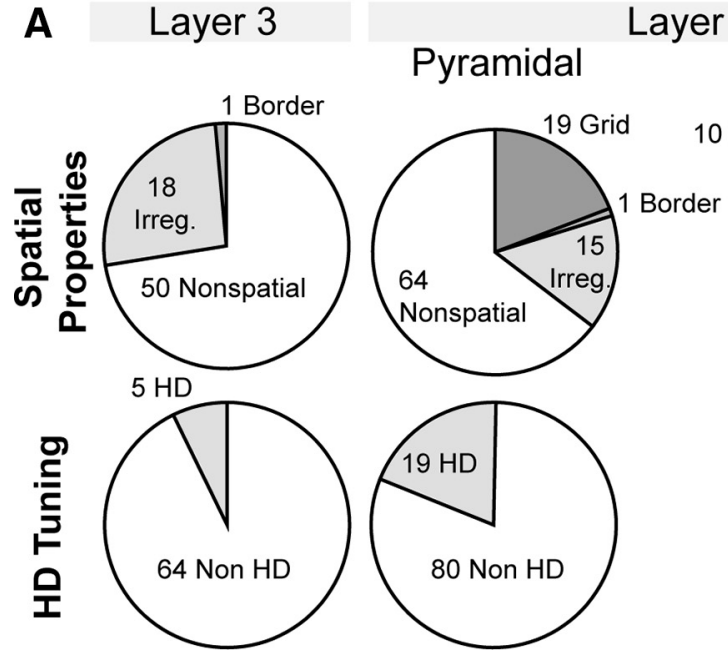

Layer 2
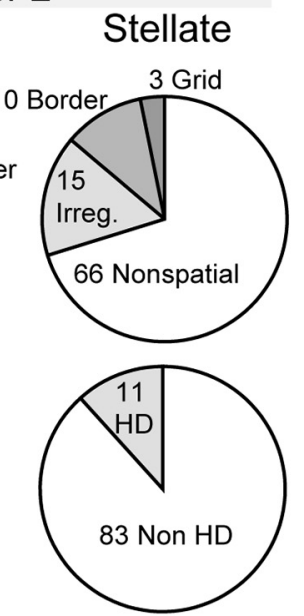

B

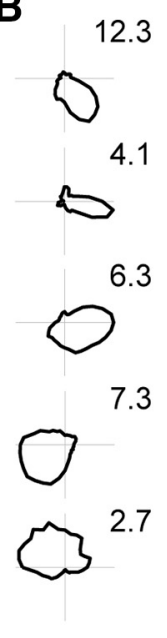

.3
C
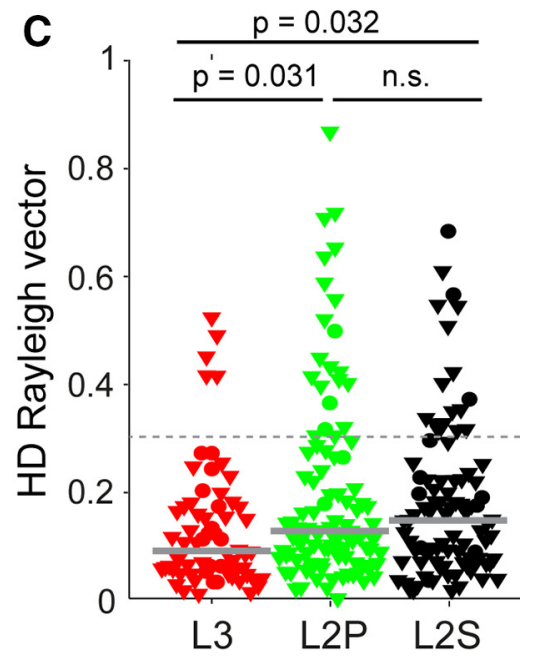

Figure 7. Spatial firing properties and head directionality of layers 2 and 3 neurons in MEC. $A$, Distribution of spatial and directional firing patterns observed in MEC layer 3 (left) and layer 2 neurons [identified plus classified in "putative" pyramidal (middle) and "putative" stellate (right) cells; data from Tang et al. 2014b shown for comparison]. B, Layer 3 head-direction cells that met the inclusion criteria (see Materials and Methods) arranged top to bottom according to the head-direction vector length. Peak firing rate in hertz is indicated next to the plots. C, Comparison of the head-direction Rayleigh vector lengths in MEC layer 3 (L3, red) and layer 2 (L2) neurons [identified plus classified in "putative" pyramidal (green) and "putative" stellate (black) cells]. Triangles indicate nonidentified recordings (juxtacellular plus tetrode). Circles indicate cells recorded and identified juxtacellularly. Horizontal lines indicate medians; $p$ values indicate result of Mann-Whitney $U$ test (Bonferroni-Holm corrected for multiple comparisons). Data from MEC layer 2 are from Tang et al. 2014b and are shown for comparison.

tained under urethane/ketamine anesthesia (Klausberger et al., 2003), where, unlike layer 2 neurons (Ray et al., 2014), layer 3 neurons $(n=13)$ lacked theta rhythmicity (average theta rhythmicity, $\left.0.8 \pm 0.2 \times 10^{-3}\right)$ and were weakly locked to ongoing theta oscillations (average locking strength, $0.32 \pm 0.15$; data not shown). Altogether, these data indicate that layer 3 neurons are distinct from layer 2 cells with respect to their weak theta rhythmicity and their average weak entrainment by theta oscillations.

When we assessed spatial discharge properties of layer 3 cells, we found that a fraction of the layer 3 neurons included in the spatial analysis (19 of $69 ; \sim 28 \%$, see Materials and Methods) carried significant spatial modulation, confirming previous reports (Sargolini et al., 2006; Hafting et al., 2008; Burgalossi et al., 2011; Domnisoru et al., 2013; Schmidt-Hieber and Häusser, 2013). However, in none of the neurons, which were located well within layer 3, did we observe clear grid or border firing patterns (Fig. 6). Rather, spatially irregular firing patterns dominated among spatially modulated neurons (Fig. 6). Surprisingly, only a small fraction of the layer 3 neurons (5 of 69) met the headdirectionality criteria (Fig. $7 A, B$ ). Although the proportion of head-direction cells did not differ statistically between layers 3 and 2 ( $p=0.069, \chi^{2}$ test), average head-direction Rayleigh vector lengths of layer 3 neurons were smaller than in layer 2 cells $(p=$ 0.0317 and $p=0.0326$ vs putative pyramidal cells and stellate cells, respectively, Mann-Whitney U test, Bonferroni-Holm corrected for multiple comparisons; Fig. 7C). The layer 2 cell sample shown here for comparison comes from our earlier work and contains identified cells and layer 2 recordings, which were putatively assigned to cell types based on temporal discharge characteristics (Tang et al., 2014b). In summary, these data indicate that theta-rhythmic discharges and headdirection-modulated responses are sparse in MEC layer 3, where on the other hand non-theta-rhythmic, spatially irregular response patterns dominate.

\section{Discussion}

Here we confirm that layer 3 is a major source of the contralateral MEC projection. Thus, layer 3 is a major hub not only for ento- rhinal-hippocampal communication, but also for interhemispheric coordination. We found that, unlike layer 2 principal neurons (Ray et al., 2014), layer 3 neurons displayed homogeneous in vitro intrinsic and in vivo spatiotemporal properties, without clear indications of bimodality. The unique arrangement of layer 3 dendrites in respect to the calbindin-positive layer 2 patches (Fig. 3) puts anatomical constraints on the inputs that these neurons might receive. Since cholinergic (Ray et al., 2014) and parasubicular inputs (Burgalossi et al., 2011; Q.T., A.B., and M.B., unpublished observations) are strongly selective for the calbindin-patch territories in layers 2 and 1 of the MEC, the fact that layer 3 dendrites largely avoid these territories makes them unlikely recipients of such inputs. Notably, cholinergic transmission has been linked to grid activity in the MEC (Brandon et al., 2011; Koenig et al., 2011; Newman et al., 2014); the fact that we observed a very low abundance of grid cells ( 0 of 69 ; however, 2 of 69 , $\sim 3 \%$, showed nonsignificant hexagonality) in our (albeit limited) layer 3 dataset might be suggestive of a causal relationship. Parasubicular neurons show the strongest theta rhythmicity of spiking among parahippocampal neurons (Burgalossi et al., 2011; Q.T., A.B., and M.B., unpublished observations); layer 2 pyramidal neurons are likely recipients of such theta-modulated inputs (Ray et al., 2014), while our anatomical observations indicate that layer 3 neurons might not (but see Canto et al., 2012). The weak theta modulation of layer 3 neurons observed here is in line with previous work (Mizuseki et al., 2009) and might be the result of the arrangement of layer 3 dendrites and their relationship to layer 2 patches.

The apparent sparseness of head directionality among layer 3 neurons is puzzling because there is a dense presubicular projection into layer 3 (Caballero-Bleda and Witter, 1993, 1994). Thus, further work will be required for resolving the functional nature of presubicular inputs to MEC layer 3, and how directional information is integrated within the local neuronal network and/or at single-cell level. Our results diverge from earlier findings on layer 3, which described dominant conjunctive responses and head directionality in this layer (Sargolini et al., 2006; Boccara et al., 
2010). Part of the discrepancy might be accounted for by different sampling methods (juxtacellular vs tetrode) between the current and previous studies, and more inclusive criteria for headdirectional tuning (Sargolini et al., 2006). We note also that sharp head-direction signals are typically observed at the dorsalmost border of the MEC (Fyhn et al., 2008; Wills et al., 2010; Giocomo et al., 2014), a region where the parasubiculum extends in a long and narrow stripe above the MEC (Burgalossi et al., 2011; Q.T., A.B., and M.B., unpublished observations). Considering the limited spatial resolution achievable with tetrode recordings, this is compatible with a parasubicular origin of sharp head-direction signals. Assessment of directionality from more ventral layer 3 locations, where tuning has been shown to be weaker (Giocomo et al., 2014) agrees well with our current data. The strength of our dataset stems from histological confirmation of the cellular/laminar origin of our recordings; we acknowledge, however, that our conclusions rest on a relatively limited sample.

Resolving the functional properties of layer 3 neurons is of significance for our understanding of spatial coding in entorhinal cortex and its downstream targets (e.g., hippocampus). Indeed a recent study has reported a majority of nonspatially modulated inputs to the hippocampus (Zhang et al., 2013), which is consistent with our average picture of layer 3 responses. We are intrigued by the very different spatial discharge patterns that we observed in the directly adjacent layers 2 and 3. Almost all layer 3 cells discharged in irregular spatial patterns and showed weak head directionality. In contrast, spatially modulated layer 2 neurons often discharged in grid or border patterns. Despite the lack of strict geometry, layer 3 discharges could provide sufficient information for decoding the animal's position in space, provided that the cells' responses are reliable and stable across time (Zhang et al., 1998; Zhang and Sejnowski, 1999). It remains to be established whether and how these irregular spatial firing patterns contribute to place-cell activity in the downstream hippocampus.

\section{References}

Abbasi S, Kumar SS (2013) Electrophysiological and morphological characterization of cells in superficial layers of rat presubiculum. J Comp Neurol 521:3116-3132. CrossRef Medline

Beed P, Bendels MH, Wiegand HF, Leibold C, Johenning FW, Schmitz D (2010) Analysis of excitatory microcircuitry in the medial entorhinal cortex reveals cell-type-specific differences. Neuron 68:1059-1066. CrossRef Medline

Behr J, Gloveli T, Heinemann U (1998) The perforant path projection from the medial entorhinal cortex layer III to the subiculum in the rat combined hippocampal-entorhinal cortex slice. Eur J Neurosci 10:1011-1018. CrossRef Medline

Boccara CN, Sargolini F, Thoresen VH, Solstad T, Witter MP, Moser EI, Moser MB (2010) Grid cells in pre- and parasubiculum. Nat Neurosci 13:987-994. CrossRef Medline

Brandon MP, Bogaard AR, Libby CP, Connerney MA, Gupta K, Hasselmo ME (2011) Reduction of theta rhythm dissociates grid cell spatial periodicity from directional tuning. Science 332:595-599. CrossRef Medline

Brun VH, Leutgeb S, Wu HQ, Schwarcz R, Witter MP, Moser EI, Moser MB (2008) Impaired spatial representation in CA1 after lesion of direct input from entorhinal cortex. Neuron 57:290-302. CrossRef Medline

Burgalossi A, Herfst L, von Heimendahl M, Förste H, Haskic K, Schmidt M, Brecht M (2011) Microcircuits of functionally identified neurons in the rat medial entorhinal cortex. Neuron 70:773-786. CrossRef Medline

Caballero-Bleda M, Witter MP (1993) Regional and laminar organization of projections from the presubiculum and parasubiculum to the entorhinal cortex: an anterograde tracing study in the rat. J Comp Neurol 328: 115-129. CrossRef Medline

Caballero-Bleda M, Witter MP (1994) Projections from the presubiculum and the parasubiculum to morphologically characterized entorhinal- hippocampal projection neurons in the rat. Exp Brain Res 101:93-108. Medline

Canto CB, Witter MP (2012) Cellular properties of principal neurons in the rat entorhinal cortex. II. The medial entorhinal cortex. Hippocampus 22:1277-1299. CrossRef Medline

Canto CB, Koganezawa N, Beed P, Moser EI, Witter MP (2012) All layers of medial entorhinal cortex receive presubicular and parasubicular inputs. J Neurosci 32:17620-17631. CrossRef Medline

Couey JJ, Witoelar A, Zhang SJ, Zheng K, Ye J, Dunn B, Czajkowski R, Moser MB, Moser EI, Roudi Y, Witter MP (2013) Recurrent inhibitory circuitry as a mechanism for grid formation. Nat Neurosci 16:318-324. CrossRef Medline

Dickson CT, Mena AR, Alonso A (1997) Electroresponsiveness of medial entorhinal cortex layer III neurons in vitro. Neuroscience 81:937-950. CrossRef Medline

Domnisoru C, Kinkhabwala AA, Tank DW (2013) Membrane potential dynamics of grid cells. Nature 495:199-204. CrossRef Medline

Erchova I, Kreck G, Heinemann U, Herz AV (2004) Dynamics of rat entorhinal cortex layer II and III cells: characteristics of membrane potential resonance at rest predict oscillation properties near threshold. J Physiol 560:89-110. CrossRef Medline

Fyhn M, Hafting T, Witter MP, Moser EI, Moser MB (2008) Grid cells in mice. Hippocampus 18:1230-1238. CrossRef Medline

Germroth P, Schwerdtfeger WK, Buhl EH (1989) Morphology of identified entorhinal neurons projecting to the hippocampus. A light microscopical study combining retrograde tracing and intracellular injection. Neuroscience 30:683-691. CrossRef Medline

Giocomo LM, Stensola T, Bonnevie T, Van Cauter T, Moser MB, Moser EI (2014) Topography of head direction cells in medial entorhinal cortex. Curr Biol 24:252-262. CrossRef Medline

Gloveli T, Schmitz D, Empson RM, Dugladze T, Heinemann U (1997) Morphological and electrophysiological characterization of layer III cells of the medial entorhinal cortex of the rat. Neuroscience 77:629-648. CrossRef Medline

Hafting T, Fyhn M, Molden S, Moser MB, Moser EI (2005) Microstructure of a spatial map in the entorhinal cortex. Nature 436:801-806. CrossRef Medline

Hafting T, Fyhn M, Bonnevie T, Moser MB, Moser EI (2008) Hippocampusindependent phase precession in entorhinal grid cells. Nature 453:1248-1252. CrossRef Medline

Honda Y, Sasaki H, Umitsu Y, Ishizuka N (2012) Zonal distribution of perforant path cells in layer III of the entorhinal area projecting to CAl and subiculum in the rat. Neurosci Res 74:200-209. CrossRef Medline

Kitamura T, Pignatelli M, Suh J, Kohara K, Yoshiki A, Abe K, Tonegawa S (2014) Island cells control temporal association memory. Science 343: 896-901. CrossRef Medline

Klausberger T, Magill PJ, Márton LF, Roberts JD, Cobden PM, Buzsáki G, Somogyi P (2003) Brain-state- and cell-type-specific firing of hippocampal interneurons in vivo. Nature 421:844-848. CrossRef Medline

Kloosterman F, Van Haeften T, Witter MP, Lopes Da Silva FH (2003) Electrophysiological characterization of interlaminar entorhinal connections: an essential link for re-entrance in the hippocampal-entorhinal system. Eur J Neurosci 18:3037-3052. CrossRef Medline

Koenig J, Linder AN, Leutgeb JK, Leutgeb S (2011) The spatial periodicity of grid cells is not sustained during reduced theta oscillations. Science 332: 592-595. CrossRef Medline

Lein ES, Hawrylycz MJ, Ao N, Ayres M, Bensinger A, Bernard A, Boe AF, Boguski MS, Brockway KS, Byrnes EJ, Chen L, Chen L, Chen TM, Chin MC, Chong J, Crook BE, Czaplinska A, Dang CN, Datta S, Dee NR et al. (2007) Genome-wide atlas of gene expression in the adult mouse brain. Nature 445:168-176. CrossRef Medline

Lever C, Burton S, Jeewajee A, O’Keefe J, Burgess N (2009) Boundary vector cells in the subiculum of the hippocampal formation. J Neurosci 29:97719777. CrossRef Medline

Mizuseki K, Sirota A, Pastalkova E, Buzsáki G (2009) Theta oscillations provide temporal windows for local circuit computation in the entorhinalhippocampal loop. Neuron 64:267-280. CrossRef Medline

Moser EI, Moser MB (2013) Grid cells and neural coding in high-end cortices. Neuron 80:765-774. CrossRef Medline

Moser EI, Kropff E, Moser MB (2008) Place cells, grid cells, and the brain's spatial representation system. Annu Rev Neurosci 31:69-89. CrossRef Medline 
Newman EL, Climer JR, Hasselmo ME (2014) Grid cell spatial tuning reduced following systemic muscarinic receptor blockade. Hippocampus 24:643-655. CrossRef Medline

Pastoll H, Solanka L, van Rossum MC, Nolan MF (2013) Feedback inhibition enables theta-nested gamma oscillations and grid firing fields. Neuron 77:141-154. CrossRef Medline

Quilichini P, Sirota A, Buzsáki G (2010) Intrinsic circuit organization and theta-gamma oscillation dynamics in the entorhinal cortex of the rat. J Neurosci 30:11128-11142. CrossRef Medline

Ray S, Naumann R, Burgalossi A, Tang Q, Schmidt H, Brecht M (2014) Grid-layout and theta-modulation of layer 2 pyramidal neurons in medial entorhinal cortex. Science 343:891-896. CrossRef Medline

Sargolini F, Fyhn M, Hafting T, McNaughton BL, Witter MP, Moser MB, Moser EI (2006) Conjunctive representation of position, direction, and velocity in entorhinal cortex. Science 312:758-762. CrossRef Medline

Savelli F, Yoganarasimha D, Knierim JJ (2008) Influence of boundary removal on the spatial representations of the medial entorhinal cortex. Hippocampus 18:1270-1282. CrossRef Medline

Schmidt-Hieber C, Häusser M (2013) Cellular mechanisms of spatial navigation in the medial entorhinal cortex. Nat Neurosci 16:325-331. CrossRef Medline

Skaggs WE, McNaughton BL, Gothard KM, Markus EJ (1993) An information-theoretic approach to deciphering the hippocampal code. In: Advances in neural processing systems, vol. 5 (Hanson SJ, Cowan JD, Giles CL, eds.). San Mateo: Morgan Kaufmann.

Solstad T, Boccara CN, Kropff E, Moser MB, Moser EI (2008) Representation of geometric borders in the entorhinal cortex. Science 322:18651868. CrossRef Medline

Suh J, Rivest AJ, Nakashiba T, Tominaga T, Tonegawa S (2011) Entorhinal cortex layer III input to the hippocampus is crucial for temporal association memory. Science 334:1415-1420. CrossRef Medline

Tang Q, Brecht M, Burgalossi A (2014a) Juxtacellular recording and morphological identification of single neurons in freely moving rats. Nat Protoc 9:2369-2381. CrossRef Medline

Tang Q, Burgalossi A, Ebbesen CL, Ray S, Naumann R, Schmidt H, Spicher D, Brecht M (2014b) Pyramidal and stellate cell specificity of grid and border representations in layer 2 of medial entorhinal cortex. Neuron 84: 1191-1197. CrossRef Medline

van der Linden S, Lopes da Silva FH (1998) Comparison of the electrophysiology and morphology of layers III and II neurons of the rat medial entorhinal cortex in vitro. Eur J Neurosci 10:1479-1489. CrossRef Medline

van Haeften T, Baks-te-Bulte L, Goede PH, Wouterlood FG, Witter MP (2003) Morphological and numerical analysis of synaptic interactions between neurons in deep and superficial layers of the entorhinal cortex of the rat. Hippocampus 13:943-952. CrossRef Medline

Varga C, Lee SY, Soltesz I (2010) Target-selective GABAergic control of entorhinal cortex output. Nat Neurosci 13:822-824. CrossRef Medline

Wills TJ, Cacucci F, Burgess N, O'Keefe J (2010) Development of the hippocampal cognitive map in preweanling rats. Science 328:1573-1576. CrossRef Medline

Zhang K, Sejnowski TJ (1999) Neuronal tuning: to sharpen or broaden? Neural Comput 11:75-84. CrossRef Medline

Zhang K, Ginzburg I, McNaughton BL, Sejnowski TJ (1998) Interpreting neuronal population activity by reconstruction: unified framework with application to hippocampal place cells. J Neurophysiol 79:1017-1044. Medline

Zhang SJ, Ye J, Miao C, Tsao A, Cerniauskas I, Ledergerber D, Moser MB, Moser EI (2013) Optogenetic dissection of entorhinal-hippocampal functional connectivity. Science 340:1232627. CrossRef Medline 